\title{
Correction
}

\section{Correction to: Lake Van (Southeastern Turkey) Experiment: Receiver Function Analyses of Lithospheric Structure from Teleseismic Observations}

\author{
Hamdi Alkan, ${ }^{1}$ (D) Hakan Çinar, ${ }^{2}$ and Sergey Oreshin ${ }^{3}$
}

Correction to: Pure Appl. Geophys.

https://doi.org/10.1007/s00024-020-02447-7

The article Lake Van (Southeastern Turkey) Experiment: Receiver Function Analyses of Lithospheric Structure from Teleseismic Observations written by Hamdi Alkan, Hakan Çınar, and Sergey Oreshin was originally published electronically on the publisher's internet portal (currently SpringerLink) on 19 February 2020 with open access. With the author(s)' decision to step back from Open Choice, the copyright of the article changed on March 2020 to (C) Springer Nature Switzerland AG 2020 and the article is forthwith distributed under the terms of copyright.

1 Department of Geophysical Engineering, Van Yüzüncü Yıl University, 65080 Van, Turkey. E-mail: hamdialkan@yyu.edu.tr

2 Department of Geophysical Engineering, Karadeniz Technical University, 61080 Trabzon, Turkey.

3 Schmidt Institute of Physics of the Earth, Russian Academy of Sciences, 123242 Moscow, Russia. 